\title{
A meta-analysis of studies on cosmetically tinted soft contact lenses
}

\section{Marjorie J Rah' \\ Jeffery Schafer' \\ Lening Zhang' \\ Osbert Chan ${ }^{2}$ \\ Lipika Roy ${ }^{3}$ \\ Joseph T Barr}

'Bausch \& Lomb Incorporated, Rochester, NY, USA; ${ }^{2}$ Bausch \& Lomb Incorporated, Asia Pacific Medical Affairs, Hong Kong; ${ }^{3}$ Bausch \& Lomb Incorporated, Asia Pacific Medical Affairs, Singapore, Malaysia
Correspondence: Marjorie J Rah Bausch \& Lomb Incorporated, 1400 North Goodman St, Rochester, NY 14609, USA

$\mathrm{Tel}+\mathrm{I} 5854 \mid 36397$

Fax +I 5853380750

Email marjorie.rah@bausch.com
This article was published in the following Dove Press journal:

Clinical Ophthalmology

10 October 2013

Number of times this article has been viewed

Background: Concerns regarding the safety of cosmetically tinted contact lenses have been reported in the literature. The purpose of this paper is to evaluate the safety of cosmetically tinted contact lenses in a large number of patients across six clinical trials that varied from 1 week to 3 months in duration.

Methods: Lenses tested included: Naturelle limbal ring daily disposable, Lacelle limbal ring daily disposable, Lacelle colored cosmetic daily disposable, Lacelle limbal ring planned replacement at 2 weeks, and Alamode traditional/annual colored cosmetic lens. The primary safety outcome was slit-lamp examination, including epithelial edema, epithelial microcysts, corneal staining, bulbar injection, limbal injection, upper lid tarsal conjunctival abnormalities, corneal neovascularization, and corneal infiltrates. High contrast $\log$ MAR visual acuity with lenses, and lens wearing time, movement, and centration, are also presented.

Results: A total of 871 subjects (1,742 eyes) and 23 clinical investigators participated in the six studies, with an average completion rate of $96.4 \%$ across all studies. The mean age of the patients was $26.8 \pm 6.6$ years, and $86.7 \%$ of participants were female. The total number of slit-lamp examinations across the six studies was 2,456 visits by eye (1,228 visits by patient). There were no slit-lamp signs $>$ grade 2 for any finding, with the exception of corneal staining in one study. In this study, grade 3 corneal staining was noted in one eye $(0.1 \%)$ at follow-up visit 1 and four $(0.6 \%)$ of all eligible dispensed eyes at follow-up visit 2 , with no eyes requiring medical treatment. No adverse events were reported during any of the trials.

Conclusion: The cosmetically tinted lenses evaluated in this meta-analysis appear to be safe when properly prescribed by an eye care professional and used in a compliant manner.

Keywords: contact lens, hydrogel, cosmetically tinted contact lens, compliance

\section{Introduction}

Cosmetic soft contact lenses represent a rapidly growing segment of the contact lens market, especially in Asian countries. According to the 2010 Study of the International Market for Contact Lenses conducted by Multi-sponsor Surveys International LLC, the use of cosmetically tinted lenses among all contact lens wearers ranges from $24 \%$ in Taiwan to $39 \%$ in Singapore (Figure 1). ${ }^{1}$ In a study of cosmetically tinted lenses in the UK, the proportion of all soft lens fits between 1997 and 2008 that were cosmetically tinted lenses has been reported to be lower than in Asian countries with significantly more females than males fitted (females $4.6 \%$ and males $1.6 \%$ ). ${ }^{2}$ In contrast with Asian countries, the authors reported that the proportion of cosmetically tinted lenses fitted in the UK declined between 1997 and 2008. ${ }^{2}$ In their analysis of international contact lens prescribing, Morgan et al reported the proportion of soft lens fits that 


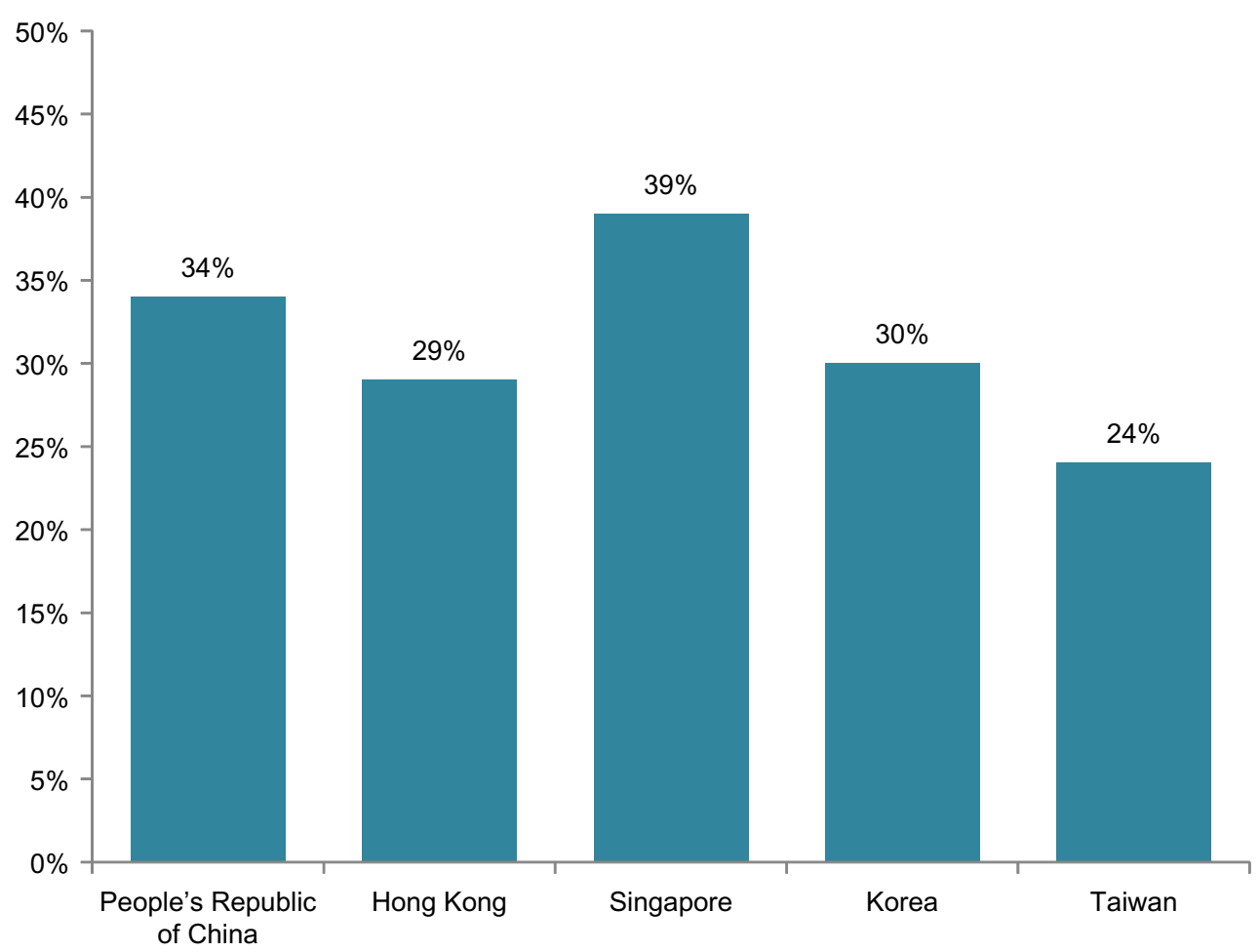

Figure I Cosmetically tinted lens use among all contact lens wearers.

were cosmetically tinted to be $1 \%$ for both the UK and the US in $2012 .^{3}$

In the People's Republic of China, cosmetic contact lens wearers tend to be younger female students. ${ }^{4}$ Compared with clear lenses, cosmetically tinted lenses are worn more for social occasions. ${ }^{4}$ In the UK, cosmetically tinted lenses were fitted to younger patients (average age $27 \pm 11$ years) compared with noncosmetically tinted lenses ( $33 \pm 13$ years), and significantly more tinted lenses were fitted for part-time wear compared with full-time wear, ie, the opposite of noncosmetically tinted lenses. ${ }^{2}$

Although there are case reports of safety concerns in the literature, there is a paucity of prospective clinical studies reporting on the safety of cosmetically tinted contact lenses. The purpose of this work was to evaluate the safety of cosmetically tinted contact lenses in a large number of patients across six clinical trials. This represents the first such large-scale report of the safety of cosmetically tinted soft contact lenses.

\section{Methods and materials}

A meta-analysis was performed on all studies in which slitlamp examination, high contrast $\log$ MAR visual acuity with lenses, lens wearing time, lens centration, and movement results from six consecutive, prospective clinical studies conducted between February 2010 and December 2011 were combined. Results from all eligible subjects at all visits while using the cosmetically tinted lenses are included. The description of each study, including study duration and study designs, for the six studies are shown in Table 1.

All studies were approved by an institutional review board and informed consent was obtained from each subject prior to participation. Subject recruitment for each study was only open to currently adapted wearers of soft contact lenses. Eligible subjects had to wear a lens in each eye and each lens must have been of the same manufacture and brand. Eligible subjects had to wear plano or require myopic correction and had to have visual acuity correctable through spherocylindrical refraction to $0.3 \log$ MAR or better in each eye. In addition, subjects had to have clear central corneas and be free of any anterior segment disorders. Subjects with slit-lamp findings greater than grade 1 or corneal infiltrates of any grade were not eligible. Subjects who had worn gas permeable lenses within 30 days or polymethylmethacrylate lenses within 3 months prior to enrollment, and those who were aphakic, amblyopic, or who required monovision, multifocal, or toric contact lenses were not eligible to participate.

Distance high contrast visual acuity was calculated as the $\log$ MAR by converting the number of letters correctly identified in the eye examination to the $\log$ MAR equivalent. Lens centration was assessed as excellent (fully centered), good (slight decentration, no corneal exposure), fair (decentration, 
Table I Profile of study design for the six studies included in the meta-analysis

\begin{tabular}{|c|c|c|c|c|c|c|}
\hline Study & Design & $\begin{array}{l}\text { Study } \\
\text { duration }\end{array}$ & Visits & Sites (n) & Study dates & Lens designs tested \\
\hline A & $\begin{array}{l}\text { Parallel, bilateral, } \\
\text { randomized, } \\
\text { open-label }\end{array}$ & One month & $\begin{array}{l}\text { Baseline, } 2 \text { weeks, } \\
\text { one month }\end{array}$ & $\begin{array}{l}10 \text { sites } \\
\text { (one Hong Kong, } \\
2 \text { Taiwan, } 7 \text { United } \\
\text { States) }\end{array}$ & $\begin{array}{l}\text { April to } \\
\text { August } 2010\end{array}$ & $\begin{array}{l}\text { Naturelle } \\
\text { Limbal ring daily disposable } \\
\text { (Bausch + Lomb) and } \\
\text { I-Day Acuvue Define } \\
\text { Accent* (Johnson \& } \\
\text { Johnson Vision Care, Inc.) }\end{array}$ \\
\hline B & $\begin{array}{l}\text { Bilateral, single } \\
\text { arm, open-label }\end{array}$ & One month & $\begin{array}{l}\text { Baseline, } 2 \text { weeks, } \\
\text { one month }\end{array}$ & $\begin{array}{l}6 \text { sites } \\
\text { (4 Singapore and } \\
2 \text { Hong Kong) }\end{array}$ & $\begin{array}{l}\text { February to } \\
\text { June } 2010\end{array}$ & $\begin{array}{l}\text { Lacelle } \\
\text { Limbal ring planned } \\
\text { replacement at two } \\
\text { weeks (Bausch + Lomb) }\end{array}$ \\
\hline C & $\begin{array}{l}\text { Bilateral, single } \\
\text { arm, open-label }\end{array}$ & One week & $\begin{array}{l}\text { Baseline, } \\
\text { one week }\end{array}$ & $\begin{array}{l}7 \text { sites } \\
\text { ( } 5 \text { Hong Kong, } \\
2 \text { Singapore) }\end{array}$ & $\begin{array}{l}\text { August to } \\
\text { November } 2010\end{array}$ & $\begin{array}{l}\text { Naturelle } \\
\text { Limbal ring daily disposable } \\
\text { (Bausch + Lomb) }\end{array}$ \\
\hline D & $\begin{array}{l}\text { Bilateral, single } \\
\text { arm, open-label }\end{array}$ & Three months & $\begin{array}{l}\text { Baseline, one month, } \\
3 \text { months }\end{array}$ & $\begin{array}{l}6 \text { sites } \\
\text { ( } 3 \text { Hong Kong, } \\
3 \text { Singapore) }\end{array}$ & $\begin{array}{l}\text { August to } \\
\text { December 2011 }\end{array}$ & $\begin{array}{l}\text { Alamode } \\
\text { Traditional/annual } \\
\text { cosmetic tinted lens } \\
\text { (Bausch + Lomb) }\end{array}$ \\
\hline$E$ & $\begin{array}{l}\text { Bilateral, single } \\
\text { arm, open-label }\end{array}$ & One month & $\begin{array}{l}\text { Baseline, } \\
\text { one month }\end{array}$ & $\begin{array}{l}6 \text { sites } \\
\text { ( } 3 \text { Hong Kong, } \\
2 \text { Malaysia, I Singapore) }\end{array}$ & $\begin{array}{l}\text { November to } \\
\text { December 20II }\end{array}$ & $\begin{array}{l}\text { Lacelle } \\
\text { Colored - cosmetic } \\
\text { Daily disposable. } \\
\text { (Bausch + Lomb) }\end{array}$ \\
\hline $\mathrm{F}$ & $\begin{array}{l}\text { Bilateral, single } \\
\text { arm, open-label }\end{array}$ & One week & Baseline, one week & $\begin{array}{l}7 \text { sites } \\
\text { (6 Hong Kong and } \\
\text { I Singapore) }\end{array}$ & $\begin{array}{l}\text { September to } \\
\text { October } 2011\end{array}$ & $\begin{array}{l}\text { Lacelle } \\
\text { Limbal ring daily disposable } \\
\text { (Bausch + Lomb) }\end{array}$ \\
\hline
\end{tabular}

Notes: *For study A, only data for Naturelle lenses are represented in the meta-analysis. Bausch + Lomb is used for Bausch \& Lomb Incorporated.

intermittent corneal exposure), or poor (incomplete corneal coverage and/or edge lift). Lens movement was assessed as adequate, excessive, insufficient, or adherence.

Slit-lamp findings for each eye, including epithelial edema, epithelial microcysts, corneal staining, bulbar injection, limbal injection, upper lid tarsal conjunctival abnormalities, corneal neovascularization, and corneal infiltrates, were graded for severity on a scale from 0 (no finding) to 4 (severe finding). Slit-lamp data from baseline visits were not included in the analysis, because it did not reflect exposure to the lenses being tested. An adverse event was defined as a sight-threatening condition, which may include but was not limited to the following: corneal ulcers, anterior uveitis (iritis), other ocular infections or inflammations, corneal scarring (central $4 \mathrm{~mm}$ ), corneal neovascularization (central $4 \mathrm{~mm}$ ), and/or permanent loss of vision.

\section{Results}

We reviewed data from six unique previously unpublished studies sponsored by Bausch \& Lomb Incorporated (Rochester, NY, USA) that included a total of 1,742 eyes ( 871 subjects) and 23 unique clinical investigators. Table 2 shows the accountability of subjects for each study. A very high proportion of subjects completed the various studies, with an average completion rate of $96.4 \%$ across all studies. The mean study duration across all studies was $29.7 \pm 28.4$ days.

The mean age of patients was $26.8 \pm 6.6$ years, and $86.7 \%$ of participants were female. Demographic data are

Table 2 Accountability of subjects for each study

\begin{tabular}{|c|c|c|c|c|c|c|c|}
\hline & Study A & Study B & Study C & Study D & Study E & Study F & Total n (\%) \\
\hline Total enrolled & 100 & 140 & 218 & 145 & 140 & 140 & 883 \\
\hline Eligible & 95 & 139 & 212 & 145 & 140 & 140 & 871 (98.6\%) \\
\hline Completed & 85 & 135 & 209 & 143 & 139 & 140 & $85 \mathrm{I}(96.4 \%)$ \\
\hline Discontinued & 10 & 4 & 3 & 2 & 1 & 0 & $20(2.3 \%)$ \\
\hline Ineligible at baseline & 5 & 1 & 6 & 0 & 0 & 0 & $12(1.4 \%)$ \\
\hline Completed & 2 & 1 & 2 & 0 & 0 & 0 & $5(0.6 \%)$ \\
\hline Discontinued & 3 & 0 & 4 & 0 & 0 & 0 & $7(0.8 \%)$ \\
\hline
\end{tabular}


provided in Table 3. Average daily lens wearing time for the study lenses was $10.1 \pm 2.8$ hours. Mean high contrast distance $\log$ MAR visual acuity with the study lenses was $0.0002 \pm 0.0715$.

Lens centration was graded as excellent or good in $97.9 \%$, $98.1 \%$, and $98.9 \%$ of patients at the dispensing, follow-up 1 , and follow-up 2 visits, respectively. Lens movement was graded as adequate in $82.7 \%, 76.5 \%$, and $83.1 \%$ of patients at the dispensing, follow-up 1, and follow-up 2 visits, respectively.

The total number of follow-up slit-lamp examinations across the six studies was 2,456 visits by eye (1,228 visits by patient). There were no slit-lamp signs $>$ grade 2 for any finding, with the exception of corneal staining in study D (Table 4). In study D, grade 3 corneal staining was noted in one eye $(0.1 \%)$ at follow-up visit 1 and four eyes $(0.6 \%)$ of all eligible dispensed eyes at follow-up visit 2 . No eyes with slit-lamp findings required medical treatment, and there were no reports of adverse events during any of the trials.

\section{Discussion}

The six prospective clinical trials reported in the present analysis provide eye care practitioners with an extensive assessment of the safety of cosmetically tinted contact lenses when properly prescribed by an eye care professional. Despite the popularity of cosmetically tinted lenses, there have been negative reports regarding safety in the literature. ${ }^{5-10}$ Compliance-related reports in the literature all have in common patient histories of receiving the contact lenses without a prescription, with no or limited care, limited handling and wearing instructions, and no follow-up examinations. ${ }^{6,8-10}$ Complications related to compliance are not limited to cosmetically tinted contact lenses. Any contact lenses, when used in a noncompliant manner, could lead to complications.

Table 3 Patient demographics summarized across all studies

\begin{tabular}{ll}
\hline Age (years) $($ mean \pm SD) & $26.8 \pm 6.6$ \\
Sex & \\
\% female & 86.7 \\
$\quad \%$ male & 13.3 \\
Race & 100 \\
$\quad \%$ Asian & $-3.30 \pm 1.7$ \\
Baseline sphere, D (mean \pm SD) & $-0.40 \pm 0.4$ \\
Baseline cylinder, D (mean \pm SD) & \\
Iris color & 96.4 \\
\% brown & 1.6 \\
\% hazel & 2.0 \\
\% other & $10.4 \pm 2.6$ \\
\hline Prestudy average daily lens wear time, hours (mean \pm SD) &
\end{tabular}

Abbreviations: SD, standard deviation; $\mathrm{D}$, diopters.

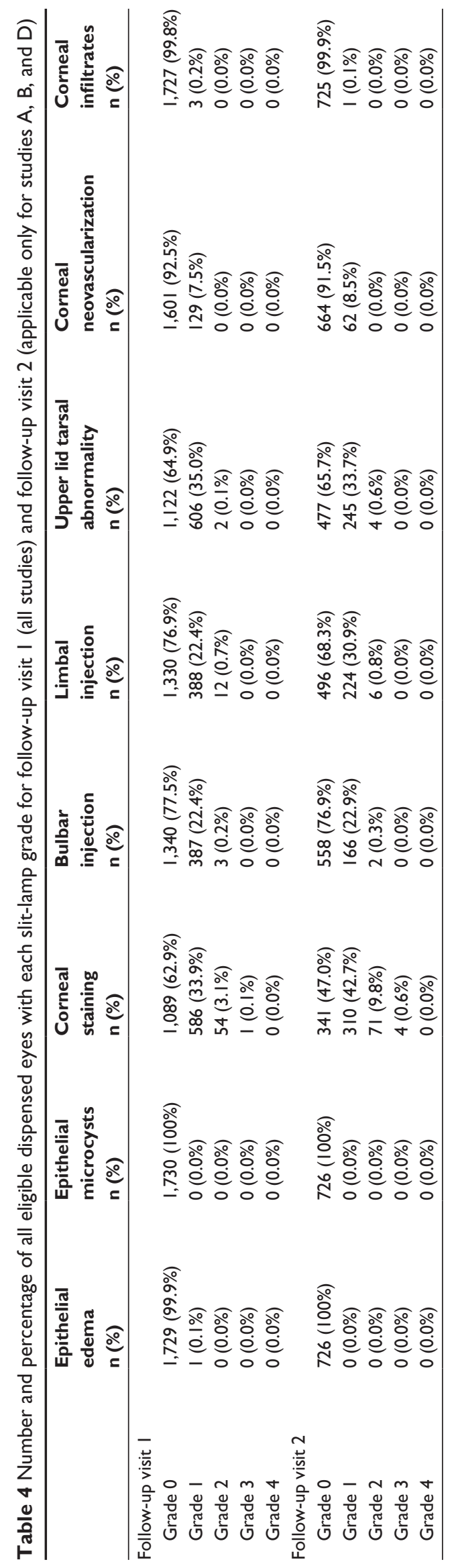


The key differences between the six studies described here and previous reports in the literature are compliance-related and education-related. When patients are properly fitted, instruction is provided, and follow-up examinations are performed, as in the six studies presented here, cosmetically tinted lenses are safe and effective. Wearers in the present investigation were experienced wearers who had, on average, myopic refractive error, which is not the case with previous compliance-related reports. This, along with the controlled nature of a clinical trial, could account for the increased safety margin in the present work.

In 2003, Steinemann et al reported six cases of ocular complications related to use of cosmetically tinted contact lenses obtained from unlicensed retail vendors. ${ }^{10}$ None of the patients had previously worn contact lenses for vision correction, and all patients had purchased the lenses without a prescription from vendors such as gas stations, flea markets, video stores, grocery stores, or mini marts. None of the patients had an accompanying eye examination, proper lens fitting, wear and care instructions, or follow-up. The authors stated that "with proper fit and appropriate instruction and follow-up by an eye care professional, the risks of decorative cosmetic contact lenses can be minimized, and lenses can be worn safely".

A subsequent publication by Steinemann et al in 2005 surveyed 159 patients who reported for routine care regarding their use and experience with cosmetically tinted contact lenses. ${ }^{9}$ Twenty-three percent of those surveyed reported they had used decorative contact lenses, and 74\% reported that their friends used decorative cosmetic lenses. Patients using the lenses reported obtaining them from unlicensed vendors approximately $41 \%$ of the time. The authors also reported 12 cases of patients who experienced complications while wearing cosmetically tinted contact lenses. All of the patients in these case reports were naïve contact lens wearers who obtained the lenses without prescription, fitting, instructions, or follow-up examination. Risk-taking and noncompliant behavior were also noted by the authors. More recently, Singh et al reported 13 cases of complications in patients wearing cosmetically tinted contact lenses. ${ }^{8}$ Much like the cases reported by Steinemann et al, none of the patients were aware of or instructed about proper lens handling techniques prior to use, and poor compliance was a common factor in all cases.

A case report by Lee et al illustrates the worst extreme of the consequences of noncompliance with soft contact lenses. ${ }^{6}$ They reported on a 17 -year-old female cosmetically tinted contact lens wearer who presented with Acanthamoeba keratitis. The patient had purchased the lenses over the Internet with no instructions on care and handling. In addition, although she reported use of a multipurpose solution to care for her lenses, she also admitted to occasionally rinsing and storing the lenses in tap water.

\section{Conclusion}

The studies presented in this report provide direct clinical evidence of the safety of the cosmetically tinted lenses tested. Ninety-nine percent of slit-lamp grades for corneal staining were $\leq 2$ and there were minimal slit-lamp findings $>2$ across the six studies in a total of 1,742 eyes (871 patients) for a total of 2,456 slit-lamp examinations by eye $(1,228$ by patient). The cosmetically tinted lenses evaluated in this report appear to be safe when properly prescribed by an eye care professional and worn by experienced users. With the increasing consumer demand for cosmetically tinted contact lenses, there is a need for eye care professionals to encourage compliance and proactively engage consumers on the wear and care of contact lenses.

\section{Disclosure}

The authors were employees of Bausch \& Lomb Incorporated, Rochester, NY, USA, at the time of writing this report.

\section{References}

1. The 2010 Study of the Intern'l Market for Contact Lenses conducted by Multi-sponsor Surveys International LLC. Available from: http:// multisponsorinternational.com/. Accessed September 30, 2013.

2. Morgan PB, Efron N. Patterns of fitting cosmetically tinted contact lenses. Cont Lens Anterior Eye. 2009;32(5):207-208.

3. Morgan PB, Woods C, Tranoudis IG, et al. International contact lens prescribing in 2012. CL Spectrum. 2013;28(1):31-44.

4. China Contact Lens Segmentation Study - Quantitative. Sep 2011. Available from: http://www.ipsos.com/. Accessed September 30, 2013.

5. Cho P, Chan KY. Permancy of pigments on coloured contact lenses a pilot study. Presented at the 8th Asia Cornea and Contact Lens Conference, Hong Kong, People's Republic of China, April 26-27, 2012.

6. Lee JS, Hahn TW, Choi SH, Yu HS, Lee JE. Acanthamoeba keratitis related to cosmetic contact lenses. Clin Experiment Ophthalmol. 2007;35(8):775-777.

7. Osborn Lorenz KO, Pinto D, Kakkassery J. AFM and SEM analysis of limbal ring contact lenses. Optom Vis Sci. 2012;89: Abstr 125610.

8. Singh S, Satani D, Patel A, Vhankade R. Colored cosmetic contact lenses: an unsafe trend in the younger generation. Cornea. 2012;31(7): 777-779.

9. Steinemann TL, Fletcher M, Bonny AE, et al. Over-the-counter decorative contact lenses: cosmetic or medical devices? A case series. Eye Contact Lens. 2005;31(5):194-200.

10. Steinemann TL, Pinninti U, Szczotka LB, Eiferman RA, Price FW Jr. Ocular complications associated with the use of cosmetic contact lenses from unlicensed vendors. Eye Contact Lens. 2003;29(4):196-200. 


\section{Publish your work in this journal}

Clinical Ophthalmology is an international, peer-reviewed journal covering all subspecialties within ophthalmology. Key topics include: Optometry; Visual science; Pharmacology and drug therapy in eye diseases; Basic Sciences; Primary and Secondary eye care; Patient Safety and Quality of Care Improvements. This journal is indexed on
PubMed Central and CAS, and is the official journal of The Society of Clinical Ophthalmology (SCO). The manuscript management system is completely online and includes a very quick and fair peer-review system, which is all easy to use. Visit http://www.dovepress.com/ testimonials.php to read real quotes from published authors. 